This article has been published in de Tienda Palop L., Currás B.X. (2019) “The Dignity of the Dead: Ethical Reflections on the Archaeology of Human Remains”, in Squires K., Errickson D., Márquez-Grant N. (eds) Ethical Approaches to Human Remains. Springer, Cham. https://doi.org/10.1007/978-3-030-32926-6_2. This version is free to view and download for private research and study only. Not for re-distribution, resale or use in derivative works. (C) Springer.

\title{
The Dignity of the Dead: Ethical Reflections on the Archaeology of Human Remains
}

Lydia de Tienda Palop ${ }^{1}$. Universitat de València. Departamento de Filosofía. University of Valencia. Av. Blasco Ibáñez 30, 46010. Valencia, España. lydia.tienda@uv.es

Brais X. Currás ${ }^{2}$. Universidade de Coimbra - CEAACP. Instituto de Arqueolgoia. R. Sobre Ribas 35, 3000-395. Coimbra, Portugal

\begin{abstract}
What is wrong with moving, analysing, and exhibiting an inert body of the past? Is it morally legitimate to manipulate the body or part of it that constituted the physiological essence of a subject with dignity? This chapter focuses, from a philosophical perspective, on analysing whether the notion of dignity can be applied to the human remains of a subject that no longer is. Ascribing dignity to dead bodies is problematic and needs conceptual clarifications in order to determine whether human corpses have certain moral status and should be protected or whether the notion of dignity should only be attributed to living persons. In this regard, as philosphers, we present a different notion of dignity from that used by Kant (1785) that it is commonly accepted when speaking about dignity, particularly since the Declaration of Human Rights (United Nations General Assembly 1948). In this chapter, the concepts "present dead" and "forgotten dead" are differentiated to justify that, even though the latter have not been object of special moral protection, they should be included under the concept of dignity. In addition, a notion of dignity grounded in the hermeneutical concept of understanding is presented to justify the role archaeology plays in providing a particular moral status to human remains and the material elements associated to them.
\end{abstract}

\footnotetext{
${ }^{1}$ This paper falls within the Juan de la Cierva research programme IJCI-2014-19375 funded by the Ministerio de Ciencia y Competitividad of Spain.

${ }^{2}$ This paper falls within the Fundação para a Ciência e a Tecnologia postdoctoral programme (SFRH/BPD/102407/2014) and of the research project HAR2015-64632-P, "Paisajes rurales antiguos del Noroeste peninsular: formas de dominación romana y explotación de recursos (CORUS)", financed by the Ministerio de Ciencia e Innovación and directed from the Instituto de Historia (CCHS, CSIC).
} 


\section{1.- Introduction}

Holding that people have dignity entails admitting that human beings deserve certain moral status that must be guaranteed unconditionally. This idea-that human beings themselves have a series of rights, which prevents them from being treated as mere "things" because they are an end and not a means - is at the core of the Universal Declaration of Human Rights (United Nations General Assembly 1948). This is explicitly included in its Preamble and Article 1: "All human beings are born free and equal in dignity and rights. They are endowed with reason and conscience and should act towards one another in a spirit of brotherhood".

The concept of dignity, which entails the particular moral protection of the human being as such, implies as the Declaration of Human Rights states, a set of inalienable rights, which violation supposes an attack against the physical and mental integrity of the person, which is deemed the most serious injury that can be committed (United Nations General Assembly 1948). However, even though human rights offer us a relatively imperfect moral guide to justify public policies internationally, there is a question that falls outside their coverage and of which little has been written about: the rights of the dead. While human rights extend their protection to persons as subjects of universal rights, this applies to living human beings, but overlooks the question of what happens to human beings when they die.

The question that arises is whether or not human beings who have died have the same moral status that they have when they were alive. This raises the subsidiary questions as to whether or not human beings can be holders of post mortem rights and, if so, what kind would these be, what are the limits of the dignity of the deceased, and how would it be articulated? In order to explore this question and offer considerations that allow praxis to be guided, it is first necessary to delimit the meaning of what we understand by "being dead". Death is the biological fact that supposes the extinction of the homeostatic state inherent in living organisms (DeGrazia 2017). In short, death is a category that allows bodies to be divided into corpses and organisms, the latter of which have active metabolic functions that are perpetrated in the time lapse. The conversion of a corpse, namely the change in state or form, responds to an evolutionary process of biochemical decomposition that transmutes into another type of organism or simpler matter that are no longer the subject itself (Pinheiro 2006; Janaway et al. 2009). However, during the decomposition process, taphonomic factors (e.g. entomology, bacteria, and the general burial environment) rarely result in the complete obliteration of a body. The fact that a subject endowed with moral status may die divides the question of dignity into two differentiated levels of analysis: on the one hand, what concerns the dignity of the dead as subjects who, at a specific moment, had a life, including tangible and intangible aspects, which was not only physiological, but also biographical; on the other hand, the dignity of the dead as beings that have an entity despite being physically dead and regardless of the consideration of the individual's past life. The latter refers to the dignity of the material human remains per se as worthy of being respected for their condition of being a corpse or part of it, and not only because they belonged to a particular living individual. This distinction becomes crucial when attempting to answer ethical questions that archaeologists and anthropologists face. Therefore, this chapter will focus, from a philosophical perspective primarily, on analysing the second level of dignity 
mentioned - the dignity of dead bodies - which needs conceptual clarifications in order to determine whether human corpses possess a certain moral status and, therefore, are entitled to special protection or whether dignity can only be ascribed to living persons. In this regard, we will present a different notion of dignity from that used by Kant (1785), and that it is commonly accepted when speaking about dignity, particularly from the Declaration of Human Rights (United Nations General Assembly 1948), in order to justify that archaeology can play a key role in providing a particular moral status to human remains.

\section{2.- The Question of Human Dignity Regarding the Dead}

The concept of "human dignity" that is currently assumed in the Western tradition is the result of its own history of thought. In the present day, in the wake of the Kantian tradition, when speaking of dignity in the philosophical realm, dignity refers to an autonomous capacity that characterises the human being as a subject with a will, that is, a being capable of having desires and volitions that may justify their actions. In Article 1 of the Universal Declaration of Human Rights (United Nations General Assembly 1948) it is stated that "all human beings have an inherent dignity and inalienable rights that must be respected". However, the nature of such dignity is not just a metaphysical exceptionality worthy of respect for human beings with regards to other living beings but, in spite of it being considered an ontological attribute, its definition is closely linked to the notion that the human being is a free being. The sophisticated argument that underlies dignity is articulated in relation to another concept no less complex: autonomy as developed by Kant (1785). According to Kant, human beings are worthy of unconditional respect because they are autonomous beings, capable of being governed according to their own will, and not by submission to an external will. The actions of human beings have in themselves a certain moral form, that is, they are the result of the exercise of their freedom that is substantiated in the right government of their reason, which gives them the ends to which they obey. Human beings are sovereign by virtue of that inner freedom that in turn constrains them by the moral law.

Linking dignity and freedom, and therefore autonomy, entails the consideration that only some particular living beings, namely human beings due to their moral nature, can be considered as deserving respect granted by their ineherent dignity. From this paradigm of thought, as Kant (1785) himself observed, those non-rational beings can hardly be autonomous and therefore considered ends in themselves:

...every rational being, exists as an end in himself and not merely as a means to be arbitrarily used by this or that will... Beings whose existence depends not on our will but on nature have, nevertheless, if they are not rational beings, only a relative value as means and are therefore called things. On the other hand, rational beings are called persons inasmuch as their nature already marks them out as ends in themselves. (Kant 1785, 1998 [Ak 4, 428]) 
It is true that Kant (1798) left (non-human) animals out of the group of beings with dignity because Kant believed that (non-human) animals were not rational and lack will:

The fact that the human being can have the representation "I" raises him infinitely above all the other beings on earth. By this he is a person....that is, a being altogether different in rank and dignity from things, such as irrational animals, with which one may deal and dispose at one's discretion. (Kant 1798, 2010 [Ak 7, 127])

Following the same logical argument, the dead would also be excluded from this group, because the bodies of the dead have lost their rational essence. A dead human being is not a rational being because although their physical remains survive, their ability to reason has ceased. According to the Kantian notion laid out, it is possible to infer that while the dead being is not subject to desires and volitions in their new state, the concept of dignity cannot be applied to them. The dead individual is no longer an autonomous being, in Kantian terms this is an end in itself because they are no longer capable of giving themselves maxims of action leading to universal laws; they are simply no longer an individual because they have extinguished their active persistence.

However, Scarre (2013), who has worked extensively on these issues, provides an insight that stems from Kant's concept of dignity. In principle, it is possible to state that - for example - there is something that disgusts the human being when a human skull is used as an ashtray (Scarre 2003) or a drinking glass (Norum 2015). Apparently, there is something morally wrong in using human bones for mundane functions. Human remains do hold a certain sacredness that seems to persist beyond their mere vital status.

Scarre $(2003,2013)$ understands that the Kantian argument does provide a solution to the aporia mentioned around the dignity of death. Although a material body may be inert because life has abandoned it, the subject has not disappeared completely, but survives in memory. Indeed, the memories, ultimately the lived history of a subject, are part of their essence and, therefore, should be regarded as deserving respect. The damage that occurs on the memory of someone in their future is corrosive and produces an injury to the essence of the subject, even if they are no longer alive. Scarre (2003) notes that the subject is made up of tangible and intangible elements, and the latter can be the object of posthumous dignity without compromising the logic of the argument that links dignity with moral freedom. The way in which Scarre (2003) interprets Kant's notion of dignity understands that, analogous to the fact that the living being has interests, the dead would have them if they could have interests. It could be assumed that the living subject would not like to be slandered in the future, or that their memory would be vilified, but that their memory remained intact and respected in a dignified manner. Similarly, this assumption can be applied to human being's material remains. It is understandable that a human being would want their remains treated in a dignified manner and not to be used for heterogeneous purposes other than eternal rest. However, the basic problem that hinders Scarre's (2003) argument, drawn from Kant's (1785) thesis, is that dignity in itself can only be advocated for rational beings endowed with autonomy. From the Kantian (1785) thesis on the subject of dignity, it is difficult to infer an ontological property possessed by bodies when they are devoid of any rational faculty, because what gives dignity to a being is precisely the moral law that the rational being, according to their autonomous, 
will give to themselves. That said, autonomy is, then, the foundation of the dignity of human nature and of all rational nature. As Kant (1785, 1998, 42-43 [AK 434, 32]) states:

In the kingdom of ends everything has either a price or a dignity. What has a price can be replaced by something else as its equivalent; what on the other hand is raised above all price and therefore admits of no equivalent has a dignity. What is related to general human inclinations and needs has a market price; that which, even without presupposing a need, conforms with a certain taste, that is, with a delight in the mere purposeless play of our mental powers, has a fancy price; but that which constitutes the condition under which alone something can be an end in itself has not merely a relative worth, that is, a price, but an inner worth, that is, dignity. Now, morality is the condition under which a rational being can be an end in itself, since only through this is it possible to be a lawgiving member in the kingdom of ends. Hence morality, and humanity insofar as it is capable of morality, is that which alone has dignity.

Scarre $(2013,243)$ recognises that Kant did not specifically deal with "the issue of archaeological disturbance of the dead" and, therefore, interprets the texts on the grounds that "humanity deserves our respect wherever we find it". Interred remains are not simply inanimate matter, like sticks and stones. They are the relics, whether whole, decayed, or the skeletal remains of human beings. To treat human remains without any regard to who they were, shows disrespect to those living persons and to humanity itself (Scarre 2013).

Conceiving that the material remains of a human body have dignity because they belonged to a rational being that no longer is, as Scarre's (2013) argument maintains, entails assuming certain premises, such as that the physical body belongs to a rational being, namely, it is its property. If one considers the physiological remains after death as belonging to a rational being that was and no longer is, it would be essential to trace the nature of the effective link between the physical matter that remains and the subject that no longer exist. To show that there is a link would imply understanding that the subject is not in the physical world but that it may well inhabit another, and thus all damage to their remains is detrimental to the subject that was and even to their memory. On the contrary, if it is not admitted that the subject that was does continue having a rational essence in some way even dead, a link cannot be traced between the material remains and a will belonging to the subject that was, as Scarre (2013) intends, because those remains belong to no one: the person no longer exists.

The difficulty of ascribing dignity to corpses per se is evident for the following reasons: the very concept of dignity is limited in the Kantian sense, since it is constrained by the rational faculty of a being that by virtue of this faculty is an autonomous subject. Therefore, within this theoretical framework, the moral protection given to a being is determined by their own ability of being a moral subject, capable of morally binding themselves. If the efficient link between the material remains and the subject that was is not shown in a reliable manner, it is very difficult to justify the attribution of an inner dignity to a corpse in these terms. At most, if the connection between the subject that was and the human remains cannot be proved, it is only possible to ascribe dignity to a corpse due to the symbolic capability of the human being. 


\section{3.- The Symbolic Attitude Towards Death: Biological and Material Remains}

The human being is aware of their own finitude and this configures their way of being in the world. Conscious of its physical materiality, it has a transcendental vocation, which determines its actions. The philosophical tradition has treated the issue of death as one of its major concerns, seeking the meaning and understanding of the particular being that is the human being with their finitude and their conscious desire for immortality. Surely for this reason, the human being by virtue of their overdeveloped imagination is also a symbolic being (Ortega y Gasset 2004). Human beings need ritual and sacralisation to understand themselves and this awareness of metaphysical eternity, together with their material finitude, leads them to build bridges between the physical world and the celestial. In this sense there is a clash of interests between the aims and methods of modern archaeology and the symbolic nature of the human being, which is, in itself, problematic.

Regarding the treatment of human remains we find different perspectives depending on the academic school or the country; there is no consensus about this issue within the academic community. A sociological study carried out by Rajala (2016) exploring the opinions of the archaeologists on their excavations in a pre-Roman necropolis in Italy, shows that the typical position of archaeologists is to assume death neutrally, as an object of study and, in this sense, the human remains analysed would be considered dehumanised biological material. The concerns that would arise from these positions in relation to funerary archaeology primarily relate to financing problems or with the degree of preservation of the remains rather than moral considerations of any kind. However, these results contrast with those obtained in England (Rajala 2016), where the approaches to the object of study responds to a greater tendency to humanise the remains, which leads to greater concern for the specific treatment that is given to human material.

The process of humanising biological remains raises the moral problems that archaeology and physical/biological anthropology must face. Humanising implies dignifying in the sense of providing a moral status to the object of study that transcends its mere reification and from it derives practical rules of action of respect. Consequently, the question, what is wrong with moving, analysing, and exhibiting an inert body of the past? is transformed into: is it morally lawful to manipulate the body or part of it that constituted the physiological essence of a subject with dignity?

As observed in the previous section of this chapter, following Scarre's (2013) approach, it would not be morally legitimate to treat the material remains of a subject disrespectfully because that subject as being endowed with will, following the Kantian wake, is an end in itself. Apparently, the deceased's will does not disappear because of the material fact of death, but it is possible to attend to the survival of the subject in their memory and in what we understand that their will may have been. Following this logic of respect for the will of the dead, as Scarre does, we find an added difficulty. To speak about will, which is an intangible element, opens the possibility to transcend temporality and extends the concept of dignity that guarantees the moral status to the remnant biological remains of the subject. Nevertheless, it is necessary to notice a subtelety: respecting the will of the subject does not only entail the preservation of their memory through the physical conservation of their remains, but also includes respect for their religious and cultural beliefs. The human being possesses the ability to have religious and cultural conceptions 
that, when they are voluntarily sustained, shape their life plans, and in this rational project that human beings are capable of designing through their will, they often include their conception of death and their transcendence (Nussbaum 1992). This will, before the act of death, is manifested not in the human remains themselves that can be actively preserved or deliberately eliminated, but in all the complexity of the ritual that accompanies the body. It is true that mortuary acts are perpetrated by relatives or human beings who survive and who have had some proximity, and we cannot always affirm with certainty that they are the result of the testamentary inheritance of a conscious will of the deceased. But what we can affirm is that those who received ritual burial were immersed in a group with certain beliefs that responded to a determined will.

In this sense, the ethical considerations related to the handling of funerary remains, which are addressed by archaeological and anthropological research, should not only deal with the bodies, but everything that surrounds/is associated with the burial: its symbolical contextualisation. The dignity of the will of a human being concerns all the materiality related to death. This includes the body and associated personal goods and clothing as well as the grave, and the objects and artefacts with a symbolic meaning that accompany the deceased that proclaim and remember their death. Death is more than the inert body. The ethical dilemmas faced by archaeologists do not focus exclusively on the biological remains of the individual but on everything that is carried along with it, and in all the elements that mark the memory of their life and the materiality of their death.

Thus, for example, the moral problem is not only to transfer, manipulate, analyse, and exhibit the remains of the person buried in a prehistoric megalithic mound, but also to open and destroy their burial. Megalithism implies a monumentalisation conceived to exhibit death (Criado 1989). The process of excavating the mound and removing all its structure subverts the will of the person, who conceived and ordered to erect that monument so that it would last and be contemplated. Alongside the body, objects such as jewellery, weapons, various utensils, ceramic pots, and plant materials are also found. These artefacts are not found in the burial by chance, but possess a strong symbolic content: the conception of transcendence in the death of the subject is ungraspable without encompassing the totality of the ritual. Especially when, in many burials, we no longer find a complete, articulated body, either because of the treatment it received as part of the funerary ritual (e.g. cremation) or because the organic remains have disintegrated as a result of decomposition.

If the archaeological investigation only considered human remains as the only one materiality susceptible to moral protection, in many cases there would be no moral crime for the desecration of the grave. This assessment could be taken into account and effectively limit the ethical protocols for the case that a body or parts of it is left in the burial, but this limitation would be inconsistent with the fact of justifying the moral status of the biological remains by their link to an intangible will. Ethical considerations must go beyond the anthropological and archaeological use of the biological remains of death (the skeleton or the mummified body), and include the use of the memory of death, and therefore of the totality of the materiality surrounding the deceased. The ethical use of the biological remains of the factum of death cannot be separated from the symbolic materiality that surrounds it. 
Therefore, in principle, several factors can be distinguished that relate to the treatment of the material remains of death, namely the moral consideration that a cultural community, with its values, traditions, and beliefs, gives to the grave and its ancestors that therefore would have a consideration of moral respect. In this case, graves and bodies are not considered to have a universal value worthy of being respected by themselves, but what is respected is the will in the death of the subject that was previously alive, inserted in a culture that possesses those values and beliefs. This consideration-the need to respect the values and beliefs of every culture - is very different from that which considers that the human being, even when dead, must be deserving of an unconditional respect. This last statement is a universal maxim that is situated on a different plane than the culture that supports the protection of the ancestors as a basic belief. Can archaeology then continue its research without desecrating this universal moral imperative? Is this universal law a construct that cannot go beyond the limits of closed cultural systems?

The cultural aspects are particular, but the symbolic nature of the human being as an imaginative being is universal. Therefore, we can grant that regardless of the belief in which they followed, we must recognise them as having a certain symbolic vocation that, of course, covers the act of death. It can hardly leave a human being indifferent, the use of a skull as an ashtray, unless that representation as an ashtray is also invested with a symbolic halo related with the cultural meanings of the death and the uses of its remains. The symbols matter to the human being and, in fact, they conceive their life as an accumulation of artifices that overlap with the given naked nature (Ortega y Gasset 2004). Certainly, it can be argued that the decontextualisation of human remains and their use for purposes other than their peaceful rest can contravene the moral law of living human beings provided by their quality of rational and, also by virtue of their overdeveloped imagination, particularly their capability to symbolise. One may wonder whether the manipulation of human remains, used according to the purposes of the investigation, would fall within the category of utilisation similar to that of serving as a domestic utensil or would have a different status.

\section{4.- Forgotten Death, Present Death}

Before elucidating the moral purpose that could justify archaeological and anthropological research on human remains and funerary practices, it is pertinent to make an explanatory distinction between forgotten dead and present dead as a basis for the subsequent ethical considerations that will be made in this chapter.

In principle, in archaeological research, there seems to be no special controversy with the analysis of human remains exhumed from prehistoric and historic archaeological sites. On the contrary, there are a number of publications (see below) that raise ethical issues about the treatment that is provided to the corpses that belong to the societies of the present. For instance, the exhumation, transfer, study, conservation, and exhibition of these bodies generate, in many occasions, fiery public debates and even accusations of racism and ethnocentrism that have been uttered regarding the differential treatment of the dead on the basis of their origin (Fforde 2013). Other observations have focused on the form of body preservation and exhibition (Fletcher et al. 2014; Swain 2016), while others have discussed the relevance of repatriation and reburial (Hubert 1989; several 
chapters in Fforde et al. 2002) and the role that research should play in these processes (McClelland and Cerezo-Román 2016). Several authors have paid attention to the problems generated by the treatment of human remains from recent conflicts (Gassiot 2008; Renshaw 2013; Brown 2016), burials from the non-distant past (Anthony 2016), or from postcolonial contexts (Pearson and Jeffs 2016). Religious feelings about death have also led to conflict between researchers and the wider community; this is especially marked in the Jewish community (Kersel and Chesson 2013; Colomer 2014). In the same way, the manipulation of the human remains and the associated material elements, such as the grave or the funerary objects in Indigenous communities, has generated a wide debate since the 1970s (Layton 1989) that survives to the present day (Martínez Aranda et al. 2014). In particular, Australian Aborigines (Richardson 1989; Parker Pearson 1999; Pardoe 2013) and Native Americans (McGuire 1989; Moore 1989; Turner 1989; Zimmerman 1989; Parker Pearson 1999; Watkins 2013) have received special attention.

Archaeologists, anthropologists, and museologists are increasingly conscious of the ethical implications that the use of the materiality of "present death" entails, namely the ethical treatment due to human remains and also to the associated funerary aspects of the recent dead. They are aware that they move in a space crossed by moral, ethical, religious, and cultural conflicts. However, the study of human remains from Antiquity does not seem to provoke many controversies. The human remains of the dead, which the researchers do not consider as belonging to anyone, those who are the ancestors of nobody, have been treated as a neutral object of study, comparable to any other archaeological object (Rajala 2016). As pointed out by Parker Pearson $(1999,171)$ "The dead do not care but the living most certainly do". Frequently, archaeologists must deal with the conflicts generated by their work in Indigenous communities, religious groups, or in the memory of local groups. But these issues are diluted and blurred when the object of study derives from older contexts. Human remains that are not claimed in the present and do not arouse conflict or public controversy, have not given rise to the same reflections, particularly Palaeolithic remains, tombs from the Neolithic, Bronze Age or Iron Age, and Roman burials and epitaphs, not to mention palaeoanthropological remains of the genus Homo.

Certainly, there is currently a growing interest in the ethical issues (Fossheim 2012) and legal issues (Márquez-Grant and Fibiger 2011) that surround the study of human remains from the past, as well as their storage and display. However, as Sellevold $(2012,144)$ points out, "The further back in time, the less is the chance that the remains are identifiable as direct ancestors, and the less is the ethical concern". In the same sense, Jones and Harris $(1998,262)$, who do address the moral issues concerning modern Indigenous groups, reject the need to think of the dead who have fallen into oblivion: "where direct descendants are not identifiable, the interests of humanity in general should take precedence, and the remains should be made available for reputable scientific research. The lack of clear associations with the living also suggests that consent to undertake scientific study is of secondary importance, since what becomes pre-eminent is enhancing the material's ability to contribute to our understanding of human development and culture". Therefore, the studies that demand the reburial of a body recovered from a burial of prehistory, Antiquity, or any other forgotten culture, are extremely scarce (e.g. Scarre 2003, 2013; Shelbourn 2015). It seems that the rights or moral statute of these ancient dead would not be recognised in a similar way to those of the recent dead; those tied with 
cultural bonds to social groups and living beliefs. In archaeology, there is no morally consensual requirement to preserve the symbolic and ritual conditions that accompany the body in death and that draw its funerary worldview. In fact, only when someone claims to be related to the forgotten death does conflict arise, as in the case of the Neopagans and their claim to the reburial of prehistoric human remains in Britain (Rathouse 2016). In this sense, a new variable appears in the problem, since the link established with the materiality of death seems not to be measured in time, but in terms of cultural affinity.

In light of these considerations, the distinction between the "present dead" and the "forgotten dead" must be reconverted and include the cultural rather than the temporal dimension as a criterion of demarcation. In this way, the Present Death can be conceived as that which is linked to current cultural values and, in this sense, the remains of the deceased studied belong to living cultures. Therefore, its manipulation, transfer, and exhibition would suppose the transgression of cultural values that a collective can claim as their own.

The current archaeological praxis raises ethical dilemmas based on this distinction. In this way, preserving the dignity of a body is to preserve the dignity of the particular culture under which its burial makes sense. The concept of dignity in death, which is sustained in this paradigm, would then be firmly anchored in concrete cultural principles. One can argue that if the culture that gave meaning to the burial no longer exists, no cultural principle is violated and, therefore, apparently there would be no ethical considerations involved. However, this argumentative logic leads us back to further reflections of a similar nature as those discussed in the previous section of this chapter. The moral concern of respecting the dignity of a dead person goes beyond the particular cultural values seen in the funerary tableau. To speak of ethics means to speak of universal validity and, therefore, the reflection cannot be confined to interpret particular cultural systems. The category that justifies the moral treatment of human remains and other material objects linked to funerary rites cannot rest solely on the distinction between the "living dead", namely those do matter to a particular subject - either individual or collectiveand the "forgotten dead", those whose dignity rests on the possibility to have sponsors to ultimately raise voices in their defense.

The question that we face in this work is whether the dead have rights and dignity for themselves, regardless of their ideological, identity, religious, or sentimental link with the present. Should we return bodies of individuals from forgotten cultures of the past back to the earth? Should we replace their graves and their personal effects? We are not talking about the reburial of the bodies that certain communities and religious groups claim as their own, but about preserving the deceased's own right to keep their bodies according to their own beliefs, and to preserve their subjective sense of transcendence in death. For example, should we return the bodies - and their grave goods - from a Bronze Age burial to their original resting place? As Hubert $(1989,164)$ points out in the case of ancient Egypt, we have in-depth knowledge of the beliefs around death and the importance of not altering bodies. Should we, thus, return all the Egyptian mummies to their place of origin? The real, complex ethical problem posed lies in establishing what happens with the materiality of forgotten death: what ethical and moral principles can validate the use of 
the materiality of forgotten death, both in archaeological and anthropological research, and in its analysis and exhibition.

\section{5.- Ethical Approach to the Materiality of Forgotten Death}

The number of works that have reflected and followed this line of research are scarce (Scarre 2003; Márquez-Grant and Fibiger 2011; Shelbourn 2015). The basic argument held by these authors is that the use of bodies from archaeological sites is legitimate because it serves the knowledge of history. However, Scarre (2003) does not hold the aforementioned distinction to provide human remains with moral guarantees. The author does not focus on the forgotten death or the present death, but on death itself. Scarre $(2003,238)$ points out that "the dead retain a moral status that places constraints on what may licitly be done to them". In this regard, Shelbourn $(2015,144)$ establishes a very useful distinction between "the recently dead and the anciently dead" and raises a key question: "is archaeological research good reason to disturb the dead and their burial places?". The author (Shelbourn 2015, 144) argues that "most cultures accept that the needs of the dead must make way for the needs of the living, and the majority of exhumations occur during development or other works to meet the needs of the communities of the present. Archaeological excavation in advance of construction work is generally regarded as justified and acceptable, and may well be viewed as more respectful of the dead than excavation by cemetery clearance companies using mechanical shovels". Therefore, the manipulation of bodies would be legitimate provided certain conditions are met. This sort of research would be morally admissible if it serves the interests of the present, and as long as the research is to answer a question that cannot be answered in any other way. Nevertheless, those working with human remains should always treat them with respect and dignity.

While Shelbourn's (2015) argument opens up avenues for ethical justification, it also raises several problems. In the first place, this argument does not determine what it means to respectfully treat the remains of the death of different cultures. What one culture may deem to be worthy of respect may be a sacrilege to another; the symbolic meaning of death varies enormously from one culture to another (Bell 1997; Robben 2004). Also, we must consider that history could be seen as a form of narrative about the past imposed on subaltern groups. From these perspectives, the opening of a Neolithic tomb based on the fact that it serves historical purposes would not be sufficiently justified. As Scarre (2003, 243) points out, "those relics of humanity are being pressed into the service of a cause that is not their subjects' own" and, following this argumentative line, Scarre $(2003,243)$ argues that "it is fair to assume that none of the individuals that archaeologists exhume had expectations of being used as a learning resource". Regarding these assumptions, Scarre $(2003,246)$ concludes that "it needs to be acknowledged that there is no obvious method, and maybe no method at all, for estimating the relative moral importance of the interests of archaeologists and their audiences on the one hand, and those of the deceased subjects of their study on the other".

Scarre $(2003,247)$ proposes a solution to the aporia mentioned, arguing that the archaeologist uses the remains of death as a means to understand history for the benefit of knowledge, but also offers something in return to the dead because "Archaeology is 
one, highly effective, way of keeping in mind the reality of past lives, and so, arguably, a way of holding absurdity at bay". In this regard, Scarre $(2003,247)$ considers that "the revelations by archaeologists of the details of past lives are a stronger counter to Oblivion than the preservation of dead bodies intact in their graves". Although Scarre $(2003,247)$ notes that the archaeologist's main focus is interpreting past history rather than the willness, desires, or interests of particular individuals, it is also true that "their interpretative efforts bring back to mind patterns of living that might otherwise have been entirely forgotten”.

Certainly, Scarre (2003) offers a very good solution to the problem regarding the ethical treatment of human remains through this argument. Nevertheless, he does not address all the ethical complexities associated with the issue of the ethical treatment of human remains. Although one can justify that archaeological practice can contribute to the dignification of the past, by rescuing it from oblivion and making it known in the present, the reality is that the archaeologist works are alien to what those bodies were in life. The archaeological investigation that seeks to shed light on societies of the past has not received consent to do so from the dead.

Although there is, indeed, a very clear moral differentiation between the use of death to understand the past and the desecration of a grave, the first purpose is not enough to morally justify the manipulation of the biological remains of a human being, which is illustrated by Scarre's (2003) argument. There are instances where looters remove the dead and accompanying grave goods from their burial place. Looting graves consequently results in the loss of much historical and cultural information. Information that, on the other hand, the looter does not intend to obtain, moved by a single eagerness to benefit from everything that can be recovered from the dead and that may have a value for the looter. In contrast, the researcher, the archaeologist, and the anthropologist methodically study burials using an array of well-established techniques. They seek to gather the maximum amount of information from each context studied. Their aim is to further their understanding of the dead. The body and the burial are, for the researcher, a means to understand other worlds, other cultures, and civilisations. The researcher is at the service of the dead giving meaning to their life and also to their death. However, this argument according to which the opening of a tomb can be legitimate when it is done in order to give it a historical sense clashes with the absence of a past subject that pretends in some way the attainment of that historical sense. It is unlikely that the deceased left a message, containing information about their life, to be interpreted in the future with the purpose of serving as a source of information for researchers. In reality, the researcher is responding to a question that the deceased did not formulate and is also being assigned a narrative that is not theirs.

\section{6.- The Agathon of Bioarchaeology: The Being that Understands the Being}

The study of human remains provides researchers with data on diet, diseases, demographics, conflicts, and molecular data, including genetic data, which can inform us of the movement of populations (Roberts 2009; Mays 2010; Larsen 2015). Burials are also an open window to the symbolic and ritual realm of different cultures, which may be seen as one of the most elusive contexts to study in archaeology. Burials and grave goods 
can also inform archeologists of social structures and power relations in the past. Human remains recovered from archaeological contexts are not only a fundamental source of information but are also irreplaceable. They give the researcher answers to questions that otherwise could not be answered such as what worldview past civilisations had, what sense of transcendence, or even what moral ideas or religious systems they held.

As previously mentioned, the moral consideration of bodies does not always occupy a prominent place within research agendas of some archaeologists and anthropologists. Certainly, funerary archeology is a consolidated field of research that generates a large volume of publications (e.g. Murphy 2008; Gowland and Knüsel 2009), though these rarely address moral issues associated with working with the dead. Yet, most archaeologists deal with death in their daily work and, only in a secondary way do moral dilemmas arise. Burials are frequently opened as part of the archaeological investigation and the funerary remains are studied in specialised laboratories.

However, it should be noted that archaeological exhumations have a final purpose, which is moral, in a certain sense: understanding the original truth of human beings. Archaeology seeks to deepen knowledge and understanding and for this purpose it uses procedures that sometimes touch upon sensitive material and are therefore subject to moral discussion. Precisely because it seeks to understand causes at a primordial level, it finds ethical conflicts with the material with which it works. A drastic solution that would address this problem is to prohibit any form of anthropological analysis of human remains, which inevitably would be the end of this field of study. However, this is unlikely to happen in the near future. Another very different solution is to set limits and protocols for ethical action as a result of moral reflections.

As outlined in the previous section of this chapter, the distinction between the "forgotten death" and the "present death" offers a first and apparent explanation that those dead, who are considered deserving of moral respect, are those with whom we share a greater affinity based on cultural and chronological proximity. That is, they are closer to our current mindsets, and it is possible to find certain community bonds by sharing similar mental categories. A few bones from the Neolithic do not produce the same discomfort as a "fresh" body of the last century. This affirmation reaches its extreme in the consideration of pre-sapiens, whose dehumanisation can become absolute.

We agree with Scarre $(2003,2013)$ that in the discovery of the forgotten dead there is a motivation of the archaeologist for returning the dead to life in a certain way and for bringing them back to memory. Indeed, recognising that these individuals did have an entity at some point, although it was lost somewhere in time, is at the core of the research. But, in addition, the search for understanding-as already noted by the phenomenological-hermeneutic tradition initiated by Heidegger $(1927,1947)$ and continued by Gadamer (1992) - is always an act of opening to alterity and in the case, of the ancient dead, what was forgotten.

Therefore, archaeologists that study human remains do not pursue an exhibitionist ridicule of the being that was, but the manifestation of a finite desire to revive the memory of that individual. Well-conducted archaeological practices restore dignity to the subject by reconstructing and respecting their memory. Certainly, it could be said that the indifference to the subjects that were by forgetting the dead is one of the damaging acts 
that could be committed against a human being or a group of human beings that form a particular society or social group. From this point of view, there would not only be a scientific interest in carrying out archaeological research but a moral imperative of a particular nature: understanding in order to bringing back the dead in a certain way. In this sense, archaeological research cannot become pillage because it would also destroy the memory of the subject that was. On the contrary, moral recognition and an understanding attitude towards the remains, the grave, and the funerary tableau, prevents oblivion happening. Every practice that may disturb and modify the memory of the dead, this may include destroying or altering their human remains and associated funerary objects, may be harmful for the subject that was and could only be accepted when the comprehensive goal that could be achieved would be of greater benefit to preserve the worthy memory of the dead.

Yet the question of why good archaeological practice may well serve to provide a moral justification for manipulating human remains is still not sufficiently resolved. Certainly, the will of the deceased, or the lack of it, to be explained or understood can be adduced to avoid arbitrariness in the treatment of the remains of archaeological research, but this question is independent of the consideration of their dignity and their moral status as a dead being. As we have argued, dignity applies to the living because of its quality of being moral, which entails rational subjects with autonomous will, and therefore its protection and moral guarantee could hardly be extended to beings without rational will. However, a moral dimension of the human being, different from that Kant held, based on the autonomy of the will, grounded in Heideggerian roots, is still redeemable, precisely due to that rational capacity that is primordial and prior to autonomy itself: the capacity to understand. The humanitas can be conceived following the path of thought inaugurated by Heidegger $(1927,1947)$ as that opening to the being that is proper to the human being (dasein), and in which takes place the event of understanding that is primarily moral because it is open to the truth of being. In this regard, Heidegger $(1947,271)$ argues that

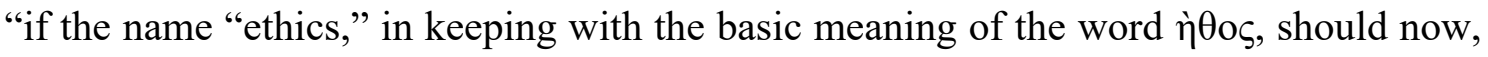
say that ethics ponders the abode of the human being, then that thinking, which thinks the truth of being as the primordial element of the human being, as one who exists, is in itself originary ethics. However, this thinking is not ethics in the first instance because it is ontology".

The subtlety that can be drawn from Heidegger's thought consists in linking the moral and the original truth of the dasein, which implies giving the human being new moral possibilities beyond the concept of Kantian dignity, grounded in the autonomy of the end in itself, which was outlined in the introduction of this chapter. The notion of dignity that stems from Heidegger's theory provides a new solution to the problem of ascribing moral status to the human remains because as argued by the philosopher "the human being is not the lord of beings. The human being is the shepherd of being. Human beings lose nothing in this "less"; rather, they gain in that they attain the truth of being. "They gain the essential poverty of the shepherd, whose dignity consists in being called by being itself into the preservation of being's truth" (Heidegger 1947, 260).

The event in which the being is revealed, namely the act of original understanding, as argued by Heidegger $(1927,1947)$ and Gadamer (1992), is the most original pure moral act that can be conceived. In this regard, Heidegger $(1947,258)$ points out "homelessness 
so understood consists of the abandonment of being by being. Homelessness is the symptom of oblivion of being. Because of it the truth of being remains unthought. The oblivion of being makes itself known indirectly through the fan that the human being always observes and handles only being". From this view, the aim of understanding can hardly be ignored as an irrefutable moral imperative because it becomes the original function of the human being insofar as the dasein is the being that understands the being. The event of radical understanding that is always an act of openness to reality is configured as the window to the essential. Following the logic of the argument, we can infer that this event is more primordial when the apprehension of what is understood is closer to the essence of a human being, which ultimately as a finite being is its temporality. The understanding of death, of everything that surrounds it, and of its visible remains must ultimately be conceived as a moral act, because it is an act in which the truth of being is shown. In the archaeological investigation of human remains, the truth of the being in all its magnitude is revealed, namely, being human is being-for-death and therefore everything that surrounds archaeological research must be treated with the moral respect it originally entails.

\section{7.- Conclusion}

Through the notion of original understanding, from primarily a philosophical point of view, this chapter has laid out a different path to provide dignity and therefore moral status to human remains. Dignity should be conceived as an inner value of any being grounded in its original authenticity and not so much in its capacity to reason. The inner truth of the human being, their authenticity, which provides them with dignity, is that they are temporary beings, namely, that their inner nature is built of just time. However, the human being is aware of their own finite nature and shows a will of transcendence through different practices, such as literature, arts, and history. Their original knowledge of their inner truth and understanding that they are going to die, and their willingness to go beyond temporality, turns any practice to avoid oblivion a moral practice that gives back dignity to the human being and reminds them its original truth: that the human being is a temporary being that wishes to transcend their primary limitations. Therefore, this idea provides a philosophical basis for a revised notion of dignity that could be applied to human remains in order to establish protocols and an ethical guide based on this idea of dignity grounded in the will of transcendence and the intention to avoid oblivion that human beings essentially possess. 


\section{References}

Anthony S (2016) Questions Raised in Excavating the Recent Dead. In: Williams H, Giles M (eds) Archaeologists and the Dead Archaeologists and the Dead: Mortuary Archaeology in Contemporary Society. Oxford, University Press, Oxford, p 21-38

Bell C (1997) Ritual perspectives and dimensions. Oxford University Press, Oxford

Brown M (2016) Habeas Corpus. Contested Ownership of Casualties of the Great War. In: Williams H, Giles M (eds) Archaeologists and the Dead: Mortuary Archaeology in Contemporary Society. Oxford University Press, Oxford, p 113-138

Colomer L (2014) The politics of human remains in managing archaeological medieval Jewish burial grounds in Europe. Nordisk Kulturpolitisk Tidskrift 17 (2): 168-186

Criado F (1989) Megalitos, espacio, pensamiento. Trabajos de Prehistoria 46: 75-98

DeGrazia, David, "The Definition of Death", The Stanford Encyclopedia of Philosophy (Spring 2017 Edition), Edward N. Zalta (ed.)

Fforde C (2013) In Search of Others: The History and Legacy of 'Race' Collections. In: Tarlow S, Nilsson Stutz L (eds) The Oxford Handbook of the Archaeology of Death and Burial. Oxford University Press, Oxford, p 709-731

Fforde C, Hubert J, Turnbull P (eds) (2002) The Dead and Their Possessions: Repatriation in Principle, Policy and Practice. Routledge, London

Fletcher A, Antoine D, Hill JD (2014) Regarding the dead: human remains in the British Museum. Research Publication 197. The British Museum Press, London

Fossheim H (ed) (2012) More than just bones. Ethics and research on human remains. The Norwegian National Research Ethics Committee, Oslo

Gadamer H (1992) Verdad y método. Sígueme, Salamanca 
Gassiot E (2008) Arqueología de un silencio. Arqueología forense de la Guerra Civil y del Franquismo. Complutum 19(2): 119-130

Gowland R, Knüsel C (eds) (2009) The Social Archaeology of Funerary Remains. Oxbow, Oxford

Heidegger M (1947) Letter on Humanism. English edition: McNeil W (ed) (1998) Pathmarks (trans: Capuzzi FA). Cambridge University Press, Cambridge

Heidegger M (1927). Sein und Zeit. Tübingen, Max Niemeyer Verlag.

Hubert J (1989) A proper place for the dead: a critical review of the 'reburial' issue. In: Layton E (ed) Conflict in the archaeology of living traditions. Routledge, London, p 133169

Janaway RC, Percival SL, Wilson AS (2009) Decomposition of human remains. In: Percival SL (ed) Microbiology and Aging: Clincal Manifestations. Springer, New York, p 313-334

Jones DG, Harris RJ (1998) Archaeological human remains. Scientific, Cultural and Ethical Considerations. Curr Anthropol 39(2): 253-264

Kant I (1785) Grundlegung zur Metaphysik der Sitten. English edition: Gregor MJ (1998) Groundwork of the Metaphysics of Morals. Cambridge University Press, Cambridge

Kant I (1798) Anthropology from a Pragmatic Point of View (1798). English edition: Louden RB (2011). in Anthropology, History, and Education. The Cambridge Edition of the Works of Immanuel Kant. Cambridge University Press, Cambridge, p 227-429

Kersel MM, Chesson MS (2013) Looting Matters: Early Bronze Age Cemeteries of Jordan's Southeast Dead Sea Plain in the Past and Present. In: Tarlow S, Nilsson Stutz L (eds) The Oxford Handbook of the Archaeology of Death and Burial. Oxford University Press, Oxford, p 677-694 
Korsgaard CM (2004) Fellow Creatures: Kantian Ethics and Our Duties to Animals. In: Petersen GB (ed) The Tanner Lectures on Human Values. Tanner Lectures Volume 25/26. University of Utah Press, Salt Lake City

Larsen CS (2015) Bioarchaeology: Interpreting Behavior from the Human Skeleton. Cambridge University Press, Cambridge

Layton E (1989) Introduction: conflict in the archaeology of living traditions. In: Layton E (ed). Conflict in the archaeology of living traditions. Routledge, London, p 1-31

Márquez Grant N, Fibiger L (eds) (2011) The Routledge handbook of archaeological human remains and legislation: an international guide to laws and practice in the excavation and treatment of archaeological human remains. Routledge, Oxford

Martínez Aranda MA, Bustamante García J, López Díaz J et al (2014) Las controversias de los "materiales culturales delicados", un debate aplazado pero necesario. PH Investigación 2: 1-31

Mays S (2010) The Archaeology of Human Bones. Routledge, Oxford

McClelland J, Cerezo-Román JI (2016) Personhood and the Re-Embodiment in Osteological Practice. In: Williams H, Giles M (eds) Archaeologists and the Dead: Mortuary Archaeology in Contemporary Society. Oxford University Press, Oxford, p 3967

McGuire R (1989) The sanctity of the grave: White concepts and American Indian burials. In: Layton E (ed) Conflict in the archaeology of living traditions, Routledge, London, p 170-188

Moore S (1989) Federal Indian burial policy: historical anachronism or contemporary reality? In: Layton E (ed) Conflict in the archaeology of living traditions, Routledge, London, p 205-215 
Murphy EM (ed) (2008) Deviant Burial in the Archaeological Record. Oxbow, Oxford

Nussbaum M (1992) Human Functioning and Social Justice: In Defense of Aristotelian Essentialism. Political Theory 20(2): 202-246

Ortega y Gasset J (2004) Meditación de la técnica y otros ensayos. Alianza Editorial: Madrid

Pardoe C (2013) Repatriation, Reburial, and Biological Research in Australia: Rhetoric and Practice. In: Tarlow S, Nilsson Stutz L (eds), The Oxford Handbook of the Archaeology of Death and Burial. Oxford University Press, Oxford, p 733-762

Parker Pearson M (1999) The Archaeology of Death and Burial. Sutton, Stroud

Pearson A, Jeffs B (2016) Slave Trade Archaeology and the Public. The excavation of a 'Liberated African' Graveyard on St Helena. In: Williams H, Giles M (eds) Archaeologists and the Dead: Mortuary Archaeology in Contemporary Society. Oxford University Press, Oxford, p 97-112

Pinheiro J (2006) Decay process of a cadaver. In: Schmidt A, Cunha E, Pinheiro J (eds) Forensic anthropology and medicine. Humana Press, New York, p 85-116

Rajala U (2016) Separating the Emotions: Archaeological Mentalities in Central Italian Funerary Archaeology. In: Williams H, Giles M (eds) Archaeologists and the Dead: Mortuary Archaeology in Contemporary Society. Oxford University Press, Oxford, p 6896

Rathouse W (2016) Contemporary Pagans and the Study of the Ancestors. In: Williams H, Giles M (eds) Archaeologists and the Dead: Mortuary Archaeology in Contemporary Society. Oxford University Press, Oxford, p 333-344

Renshaw L (2013) The Archaeology and Material Culture of Modern Military Death. . In: Tarlow S, Nilsson Stutz L (eds), The Oxford Handbook of the Archaeology of Death and Burial. Oxford University Press, Oxford, p 763-780 
Richardson L (1989) The acquisition, storage and handling of Aboriginal skeletal remains in museums: an indigenous perspective. In: Layton E (ed) Conflict in the archaeology of living traditions. Routledge, London, p 189-192

Robben ACGM (ed) (2004) Death, Mourning and Burial. A Cross-Cultural Reader. Blackwell, Malden

Roberts CA (2009) Human Remains in Archaeology: a Handbook. Council for British Archaeology, York.

Scarre G (2003) Archaeology and Respect for the Dead. J Appl Philos 20(3): 237-249

Scarre G (2013) 'Sapient trouble-tombs'? Archaeologists' Moral Obligations to the Dead. In: Tarlow S, Nilsson Stutz L (eds), The Oxford Handbook of the Archaeology of Death and Burial. Oxford University Press, Oxford, p 665-676

Sellevold B (2012) Ancient skeletons and ethical dilemmas. In: Fossheim H (ed) More than just bones. Ethics and research on human remains. The Norwegian National Research Ethics Committee, Oslo, p 139-163

Shelbourn C (2015) (Preprint) Remains, research and respect: some reflections on burial archaeology and the treatment of the 'anciently dead'. In: Redmond-Cooper R (ed) Heritage, Ancestry and Law. Principles, Policies and Practices in Dealing with Historical Human Remains. Institute of Art and Law, Builth Wells

Swain H (2016) Museum Practice and the Display of Human Remains. In: Williams H, Giles M (eds) Archaeologists and the Dead: Mortuary Archaeology in Contemporary Society. Oxford University Press, Oxford, p 169-183

Turner E (1989) The souls of my dead brothers. In: Layton E (ed) Conflict in the archaeology of living traditions. Routledge, London, p 193-198 
United Nations General Assembly (1948) Universal Declaration of Human Rights. 10 December

Watkins J (2013) How Ancients become Ammunition: Politics and Ethics of the Human Skeleton. In: Tarlow S, Nilsson Stutz L (eds), The Oxford Handbook of the Archaeology of Death and Burial. Oxford University Press, Oxford, p 695-708

Zimmerman LJ (1989) Human bones as symbols of power: aboriginal American belief systems toward bones and 'grave-robbing' archaeologists. In: Layton E (ed) Conflict in the archaeology of living traditions. Routledge, London, p 216-222 